\title{
Metabolic perturbations in mutants of glucose transporters and their applications in metabolite production in Escherichia coli
}

\author{
Hwi-Min Jung ${ }^{1 \dagger}$, Dae-Kyun Im ${ }^{1 \dagger}$, Jae Hyung Lim², Gyoo Yeol Jung ${ }^{2,3}$ and Min-Kyu Oh ${ }^{1 *}$ (0)
}

\begin{abstract}
Background: Most microorganisms have evolved to maximize growth rate, with rapid consumption of carbon sources from the surroundings. However, fast growing phenotypes usually feature secretion of organic compounds. For example, E. coli mainly produced acetate in fast growing condition such as glucose rich and aerobic condition, which is troublesome for metabolic engineering because acetate causes acidification of surroundings, growth inhibition and decline of production yield. The overflow metabolism can be alleviated by reducing glucose uptake rate.

Results: As glucose transporters or their subunits were knocked out in E. coli, the growth and glucose uptake rates decreased and biomass yield was improved. Alteration of intracellular metabolism caused by the mutations was investigated with transcriptome analysis and ${ }^{13} \mathrm{C}$ metabolic flux analysis $\left({ }^{13} \mathrm{C}\right.$ MFA). Various transcriptional and metabolic perturbations were identified in the sugar transporter mutants. Transcription of genes related to glycolysis, chemotaxis, and flagella synthesis was downregulated, and that of gluconeogenesis, Krebs cycle, alternative transporters, quorum sensing, and stress induced proteins was upregulated in the sugar transporter mutants. The specific production yields of value-added compounds (enhanced green fluorescent protein, $\gamma$-aminobutyrate, lycopene) were improved significantly in the sugar transporter mutants.
\end{abstract}

Conclusions: The elimination of sugar transporter resulted in alteration of global gene expression and redirection of carbon flux distribution, which was purposed to increase energy yield and recycle carbon sources. When the pathways for several valuable compounds were introduced to mutant strains, specific yield of them were highly improved. These results showed that controlling the sugar uptake rate is a good strategy for ameliorating metabolite production.

Keywords: Sugar transporters, Transcriptome analysis, ${ }^{13} \mathrm{C}$ Metabolic flux analysis, Enhanced green fluorescent protein (EGFP), $\gamma$-Aminobutyrate (GABA), Lycopene

\section{Background}

Microorganisms have evolved with cooperation and competition in the ecosystem. In a microbial consortium, the bacteria that have fast-growing phenotypes are at an advantage to occupy their surroundings. Fast dividing organisms consume carbon substrate rapidly to generate energy for biomass formation. Interestingly, it was discovered that Saccharomyces cerevisiae is more prone

\footnotetext{
*Correspondence: mkoh@korea.ac.kr

${ }^{\dagger}$ Hwi-Min Jung and Dae-Kyun Im contributed equally to this work

${ }^{1}$ Department of Chemical and Biological Engineering, Korea University,

145 Anam-ro, Seongbuk-gu, Seoul 02841, South Korea

Full list of author information is available at the end of the article
}

to carrying out ethanol fermentation during growth in aerobic conditions, than its predecessors [1]. They rapidly consume glucose and accumulate ethanol, which is toxic to most other microorganisms. Later, they re-consume ethanol for further growth [2]. Theoretically, glucose can be completely oxidized to $\mathrm{CO}_{2}$ with production of much more ATPs from respiration than those from fermentation metabolism through glycolysis. Nevertheless, they have evolved and opted for the ethanol fermentation pathway because it is faster and easier than the lengthy process of respiration. Many researchers have observed the overproduction of organic compounds such as acetate, lactate or ethanol during aerobic growth of fast 
growing organisms, and suggested an "overflow metabolism" theory (i.e. Crabtree effect in yeast, acetate overflow in E. coli, and Warburg effect in cancer cell) [3-5]. Recently, the relationship between growth rate and acetate overflow was accurately predicted through flux balance analysis and thermodynamic modeling approaches in E. coli $[3,6]$. Moreover, the overflow was also interpreted through real estate hypothesis, which implies that the surface to volume ratio of the cell is critical for overflow [7].

Fast growing bacteria have received attention in the bioprocess industry because of their ease of handling and economic feasibility $[8,9]$. Despite its merits, there are some problems that have to be overcome for utilizing fast growing strains, such as excessive formation of by-products $[7,10]$. Formation of organic acids as by-products is accompanied by acidification of the culture broth, lowered biomass yield, and inefficient energy generation. In this aspect, a fast-growing phenotype, which is beneficial for natural selection, is not always favorable in the engineering of microorganisms. Slow but efficient growth could be helpful for pure cultures in sterilized fermenters, where the cell to cell competition is absent. The substrate uptake capability is closely related to the growth rate of microbes and furthermore, affects the acetate overflow. When adapted in a glucose-limited chemostat with aerobic conditions, Saccharomyces cerevisiae showed decrease in growth rate, but with delayed production of ethanol [11]. Similar phenomenon was observed in $E$. coli; when cultivated in low glucose condition, growth rate dwindled and little acetate was produced [12]. Additionally, non-PTS sugars could be consumed simultaneously in glucose limited condition [13].

Several major glucose uptake pathways have been determined in E. coli. Phosphotransferase system (PTS), by which glucose is transported and phosphorylated simultaneously, is an innate mechanism in almost all enteric bacteria [14]. The PTS affects diverse metabolism such as glycolysis, TCA cycle, acetate metabolism, respiration, etc., by modulating the intracellular concentration of cyclic AMP (cAMP) [15]. Additionally, glucose can be imported by non-specific transporters like $m g l A B C$ (methyl-galactoside transport system), malEFG (maltose/maltodextrin transport system), and galP (galactose: $\mathrm{H}^{+}$symporter) in E. coli [16]. When the major glucose uptake pathways were eliminated, the mutant showed declined growth rate, glucose uptake rate, and acetate production, which resembled the results of a glucose-limited chemostat study [17]. Theses physiological changes could be originated not only from slowing down of substrate uptake rate but also from perturbation of global metabolic networks. However, studies involving metabolism and its regulation by eliminating glucose uptake pathways are still lacking. Recently, omics technologies, such as transcriptomics or fluxomics, have been applied to investigate global perturbations in metabolic pathways by biochemical and environmental changes [18-21].

In this study, the glucose uptake in E. coli was impeded by removing major glucose transporters. As expected, retardation of growth was observed, little amount of acetate was produced, and biomass yield was improved in the sugar transporter mutants. Transcriptome analysis and ${ }^{13} \mathrm{C}$ metabolic flux analysis (MFA) was implemented to compare the global gene expression and carbon flux changes. The phenotypic alterations of the sugar transporter mutants are speculated to help in improving the yields of several value-added compounds, such as recombinant proteins, gamma-aminobutyrate (GABA), and lycopene. When the pathway genes for these products were introduced, higher amounts of these compounds were produced, and specific product yields were significantly improved in the sugar transporter mutants.

\section{Materials and methods Strains and plasmids}

The strains and plasmids used in this study are included in Table 1. E. coli W (KCTC 1039), provided by Korean Collection for Type Cultures (KCTC) was used as the host strain. Sugar transporter mutants were constructed by deleting PtsG (ADT74705), MalE (ADT77685), MglB (ADT75786), and GalP (ADT76576) to reduce the glucose uptake rate. Firstly, PtsG, the major glucose transporter in E. coli, was deleted by $\lambda$-red recombinase based homologous recombination, as previously described [22]. The strain was named ST2 (Table 1). Additionally, sugar transporters, such as MalE, MglB, GalP, were serially knocked out in ST2, which was named ST8 ( $\Delta p t s G$ $\triangle m a l E \Delta m g l B \Delta g a l P$ ) (Table 1). All deletions were confirmed by PCR. The oligonucleotides were synthesized from Bionics (Bionics, Seoul, Korea). The sequences of primers for gene deletions and confirmations are listed in Additional file 1: Table S1 and the plasmids used in this study are listed in Table 1.

\section{Medium and cultivation}

Luria-Bertani broth (LB; $5 \mathrm{~g} / \mathrm{L}$ yeast extract, $10 \mathrm{~g} / \mathrm{L}$ tryptone, $10 \mathrm{~g} / \mathrm{L} \mathrm{NaCl}$ ) was used in all the genetic manipulation procedures. The culture medium was supplemented with $100 \mu \mathrm{g} / \mathrm{mL}$ of carbenicillin, $50 \mu \mathrm{g} / \mathrm{mL}$ of kanamycin, $34 \mu \mathrm{g} / \mathrm{mL}$ of chloramphenicol, and $50 \mu \mathrm{g} / \mathrm{mL}$ of spectinomycin. $\mathrm{M} 9$ minimal medium $\left(6 \mathrm{~g} / \mathrm{L} \mathrm{Na}_{2} \mathrm{HPO}_{4}, 3 \mathrm{~g} / \mathrm{L}\right.$ $\mathrm{KH}_{2} \mathrm{PO}_{4}, 1 \mathrm{~g} / \mathrm{L} \mathrm{NH}{ }_{4} \mathrm{Cl}, 0.5 \mathrm{~g} / \mathrm{L} \mathrm{NaCl}, 0.01 \%$ of Thiamine$\mathrm{HCl})$ with glucose and $1 \mathrm{~mL}$ of trace elements $(2.86 \mathrm{~g} / \mathrm{L}$ $\mathrm{H}_{3} \mathrm{BO}_{3}, 1.81 \mathrm{~g} / \mathrm{L} \mathrm{MnCl} 2 \cdot 4 \mathrm{H}_{2} \mathrm{O}, 0.222 \mathrm{~g} / \mathrm{L} \mathrm{ZnSO}_{4} \cdot 7 \mathrm{H}_{2} \mathrm{O}$, $0.39 \mathrm{~g} / \mathrm{L} \mathrm{Na}_{2} \mathrm{MoO}_{4} \cdot 2 \mathrm{H}_{2} \mathrm{O}, 0.079 \mathrm{~g} / \mathrm{L} \mathrm{CuSO}_{4} \cdot 5 \mathrm{H}_{2} \mathrm{O}, 49.4$ $\mathrm{mg} / \mathrm{L} \mathrm{Co}\left(\mathrm{NO}_{3}\right)_{2} \cdot 6 \mathrm{H}_{2} \mathrm{O}$, and $\left.0.9 \mathrm{~g} / \mathrm{L} \mathrm{FeCl}_{3} \cdot 6 \mathrm{H}_{2} \mathrm{O}\right)$ per liter, 
Table 1 Strains and plasmid used in this study

\begin{tabular}{|c|c|c|}
\hline & Description & Reference \\
\hline \multicolumn{3}{|l|}{ Strain } \\
\hline ST1 & Escherichia coliW KCTC1039 & Korean collection for type cultures \\
\hline ST2 & ST1 ptsG::FRT & This study \\
\hline ST8 & ST2 mglB::FRT malE::FRT galP::FRT & This study \\
\hline STE1 & ST1 harboring pEGFP & This study \\
\hline STE2 & ST2 harboring pEGFP & This study \\
\hline STE8 & ST8 harboring pEGFP & This study \\
\hline STG1 & ST1 gabT::FRT KanR FRT harboring pGABA & This study \\
\hline STG2 & ST2 gabT::FRT KanR FRT harboring pGABA & This study \\
\hline STG8 & ST8 gabT::FRT KanR FRT harboring pGABA & This study \\
\hline STL1 & ST1 harboring pACYC DXS and pCDF Idi IspA CrtEBI & This study \\
\hline STL2 & ST2 harboring pACYC DXS and pCDF Idi IspA CrtEBI & This study \\
\hline STL8 & ST8 harboring pACYC DXS and pCDF Idi IspA CrtEBI & This study \\
\hline \multicolumn{3}{|l|}{ Plasmid } \\
\hline pKD46 & Red recombinase expression plasmid, repA, pSC101 ori, $\mathrm{P}_{\mathrm{BAD}}$ gam, beta alpha, recA, $\mathrm{Amp}^{\mathrm{R}}$ & Datsenko and Wanner [22] \\
\hline 707FLP & Flippase expression plasmid, pSC101 ori, repA, cl578, FLPe, TetR & Generidge \\
\hline pZA31 MCS & CmR, p15A ori, PLtetO, rrnB T1 & Expressys \\
\hline pEGFP & EGFP expression in pZA31 MCS & This study \\
\hline pGABA & 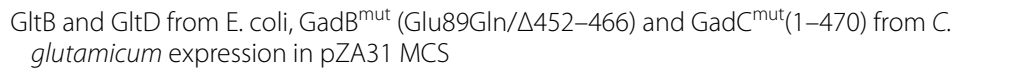 & This study \\
\hline PACYCDXS & 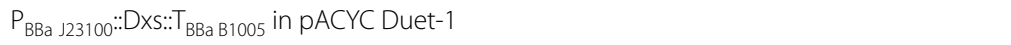 & Jung et al. [69] \\
\hline pCDF Idi IspA CrtEBI & 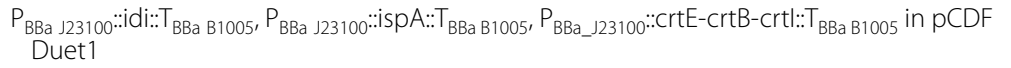 & Jung et al. [69] \\
\hline
\end{tabular}

was used for flask cultivation. Strains were cultivated in $250 \mathrm{~mL}$ Erlenmeyer flasks with $25 \mathrm{~mL}$ of working volume, at $37{ }^{\circ} \mathrm{C}$ and $250 \mathrm{rpm}$. For the production of EGFP, GABA, and lycopene, strains were cultivated in 2X M9 medium (12 g/L Na $\mathrm{HPO}_{4}, 6 \mathrm{~g} / \mathrm{L} \mathrm{KH}_{2} \mathrm{PO}_{4}, 2 \mathrm{~g} / \mathrm{L} \mathrm{NH} \mathrm{N}_{4} \mathrm{Cl}$, $1 \mathrm{~g} / \mathrm{L} \mathrm{NaCl}, 0.01 \%$ of Thiamine- $\mathrm{HCl})$ with $20 \mathrm{~g} / \mathrm{L}$ of glucose and $1 \mathrm{~mL}$ of trace elements. When strains harboring two or more plasmids were cultivated, the culture medium was supplemented with half the concentration of antibiotics. All the chemical reagents were procured from Sigma-Aldrich (Sigma-Aldrich, St. Louis, MO, US), unless otherwise mentioned.

\section{Analytical method}

The growth of strains was estimated by measuring the optical density at $600 \mathrm{~nm}\left(\mathrm{OD}_{600}\right)$ using a spectrometer DU730 (Beckman coulter, Brea, CA, US). For analysis of glucose and acetate, supernatant of the culture broth was harvested by centrifugation, followed by filtration using $0.22 \mu \mathrm{m}$ pore syringe filter. A high performance liquid chromatography (HPLC) system, having refractive index detector Waters 2414 (Waters, Milford, MA, US), with holding temperature of $45{ }^{\circ} \mathrm{C}$, was employed. SH1011 columns (Shodex, Tokyo, Japan) were used for separation and quantification of sugars, organic acid, and alcohols with temperature maintained at $75{ }^{\circ} \mathrm{C}$. Dilute sulfuric acid (10 mM) was used for the HPLC mobile phase, with flow rate adjusted to $0.6 \mathrm{~mL} / \mathrm{min}$. The concentration of glucose and acetate was calculated via linear interpolation calibration using glucose and acetate standards.

The intensity of the EGFP fluorescence was measured by a microplate reader (Synergy H1; Biotek, Winooski, VT, US) with $100 \mu \mathrm{L}$ of phosphate buffer saline-washed and diluted culture broth. Excitation was achieved at $479 \mathrm{~nm}$ and emission was detected at $520 \mathrm{~nm}$. For detection of GABA, an HPLC UV detector system (YL9100 HPLC system; Younglin instrument, Seoul, Korea) was utilized. The HPLC system was equipped with an amino acid analysis column (Eclipse Amino acid analysis; Agilent Technology, Santa Clara, CA, US) and the temperature was maintained at $40{ }^{\circ} \mathrm{C}$. Mobile phase A (40 mM $\mathrm{Na}_{2} \mathrm{HPO}_{4}$ with $1 \%$ phosphoric acid) and mobile phase B (40\% acetonitrile, $40 \%$ methanol, $\left.20 \% \mathrm{H}_{2} \mathrm{O}\right)$ were adjusted for gradient flow, with a flow rate of $1.5 \mathrm{~mL} /$ min. The culture broth was filtered after centrifugation. The supernatant $(5 \mu \mathrm{L})$ was mixed with $30 \mu \mathrm{L}$ of orthophthalaldehyde (OPA) and borate (1:5) buffer for derivatization. The derivatives were injected and analyzed at $338 \mathrm{~nm}$ using UV detectors. To measure the quantity of lycopene, $200 \mu \mathrm{L}$ of culture broth was harvested. The 
supernatant was removed after centrifugation (SMART R17; Hanil, Gimpo, Korea). About $1 \mathrm{~mL}$ of extraction solvent (mixture of equal volumes of methanol and acetone) was added to the pellet and mixed well. The solution was heated for $60 \mathrm{~min}$ at $65{ }^{\circ} \mathrm{C}$ with vigorous vortexing every $20 \mathrm{~min}$, for sufficient elution of lycopene. After extraction, the cell debris were removed by centrifugation $(21,000 \times g)$ and the supernatant was harvested. The absorbance of the supernatant was measured at $475 \mathrm{~nm}$ using a UV-Vis spectrometer (DU730; Beckman coulter, Brea, CA, US). For calculating yields, the intensity of EGFP, the quantities of GABA and lycopene were normalized by DCW and consumed glucose at early stationary phase. For measuring dry cell weight (DCW), $10 \mathrm{~mL}$ of culture broth was harvested and the supernatant was removed by centrifugation. Then cell pellet was resuspended and washed by distilled water for removal of remaining salts. The pellet was dried at $65{ }^{\circ} \mathrm{C}$ overnight and weighed.

\section{Transcriptome analysis}

The culture broths of ST1, ST2, and ST8 were harvested in early exponential phase $\left(\mathrm{OD}_{600} \sim 1\right.$ ) (Additional file 1 : Figure S1). The supernatant was removed by centrifugation and the pellet was used for RNA extraction procedures. A Trizol based RNA extraction kit (Hybrid R; GeneAll, Seoul, Korea) was used for RNA extraction. The RNA integrity number (RIN), rRNA ratio, and concentration of samples were checked by using the Agilent technologies 2100 Bioanalyzer (Agilent Technology, Santa Clara, CA, US). After satisfying the quality control criteria, samples were included for further analysis (Macrogen, Seoul, Korea). The Ribo-Zero rRNA Removal Kit and TruSeq stranded total RNA sample prep kit were used for RNA purification, following which, libraries were constructed (Macrogen, Seoul, Korea). The total RNA was sequenced by NovaSeq 6000 system (Macrogen, Seoul, Korea). For data analysis, E. coli W genomic DNA was used as reference (GCF_000184185.1_ASM18418v1) and the fold change between transcriptomes of ST1, ST2, and ST8 was calculated.

\section{${ }^{13} \mathrm{C}$ MFA experiment}

2X M9 medium with $\left[1,2-{ }^{13} \mathrm{C}\right]$ glucose (Cambridge isotope Laboratories, Tewksbury, MA, US) was used in the ${ }^{13} \mathrm{C}$ labeling experiments. One milliliter of cell broth in the early exponential phase $\left(\mathrm{OD}_{600} \sim 1\right)$ (Additional file 1 : Figure S1) was centrifuged at $15,000 \times g$ for $10 \mathrm{~min}$ at $4{ }^{\circ} \mathrm{C}$. The supernatant was removed, and the pellet was resuspended in $0.5 \mathrm{~mL}$ of distilled water. The wash process was repeated, and pellet was lyophilized in a freeze dryer (Hanil, Gimpo, Korea). Thereafter, $200 \mu \mathrm{L}$ of $6 \mathrm{~N} \mathrm{HCl}$ was added to hydrolyze the proteins at $110{ }^{\circ} \mathrm{C}$ for $24 \mathrm{~h}$.
Following hydrolysis, $200 \mu \mathrm{L}$ of $6 \mathrm{~N} \mathrm{NaOH}$ was added and the protein residues were separated using Amicon Ultra $0.5 \mathrm{~mL} 10 \mathrm{kD}$ centrifugation filters (Millipore Corporation, Burlington, MA, US). The solution was fully dried using a vacuum dryer (Hanil, Gimpo, Korea) and stored at $-80{ }^{\circ} \mathrm{C}$. The stored sample was resuspended in $50 \mu \mathrm{L}$ pyridine. Further, $80 \mu \mathrm{L}$ of $\mathrm{N}$-(tert-butyldimethylsilyl)-Nmethyl-trifluoroacetamide (MTBSTFA) was added to the derivatized proteinogenic amino acids and incubated at $70{ }^{\circ} \mathrm{C}$ for $50 \mathrm{~min}$.

The GC-MS method was adapted for an Agilent gas chromatograph, equipped with a HP-5MS capillary column $(30 \mathrm{~m} \times 0.25 \mathrm{~mm}$ i.d. $\times 0.25 \mathrm{~mm}$; Agilent Technology, Santa Clara, CA, US). A sample of $1 \mu \mathrm{L}$ was injected in 1:10 split mode with an inlet temperature of $270{ }^{\circ} \mathrm{C}$. The helium flow rate was $1 \mathrm{~mL} / \mathrm{min}$. The oven temperature of $80{ }^{\circ} \mathrm{C}$ was set for $2 \mathrm{~min}$ and then raised to $280{ }^{\circ} \mathrm{C}$ at $7{ }^{\circ} \mathrm{C} / \mathrm{min}$. Ion source temperature and electron impact ionization (EI) voltage were $230{ }^{\circ} \mathrm{C}$ and $-70 \mathrm{eV}$, respectively. Mass fragments of the proteinogenic amino acids were analyzed by the single ion monitoring (SIM) mode [23].

\section{Metabolic network model, flux analysis, and statistical analysis}

The network model used for flux calculation was constructed based on a previous report [24], which included all major central metabolic pathways, lumped amino acid biosynthesis pathways, and a lumped biomass formation reaction and G-value parameters to determine the fraction of proteinogenic amino acids from a labeled glucose.

An elementary metabolite unit (EMU) based software for ${ }^{13} \mathrm{C}$ MFA, INCA, was used [25, 26]. Metabolic fluxes were estimated by minimization of the differences between the measured mass isotopomer distributions (MIDs) of the proteinogenic amino acids and the simulated ones, using least squares regression. To find a global solution, the fluxes were estimated 10 times with random initial values and then a $\chi^{2}$-statistical test for goodness of fit was performed. The $95 \%$ confidence intervals for all estimated fluxes were computed using the sensitivity of the minimized variance-weighted sum of squared residuals to flux variations, using a built-in function of INCA $[26,27]$. Standard deviations of fluxes were determined based on previous reports $[28,29]$.

\section{Results and discussion}

\section{Phenotype characteristics of mutation in sugar transporters}

Many microorganisms adopt the phosphotransferase system (PTS) for efficient and rapid uptake of glucose. When glucose is transported to the intracellular space through PTS, PtsG (glucose-specific EIICB component) catalyzes 
the phosphorylation of incoming glucose with its translocation across the cell membrane. In the absence of $p t s G$, other sugar transporters that have broad specificity, such as $\mathrm{Mgl}$ (methyl-galactoside transport system), Mal (maltose/maltodextrin transport system), and Gal (galactose: $\mathrm{H}+$ symporter) play a major role as glucose transporters [17]. In order to hinder glucose uptake, major glucose uptake pathway genes were deleted (ST2: $\Delta p t s G$, ST8: $\Delta p t s G \Delta m g l B \Delta m a l E \Delta g a l P)$ in this study.

Escherichia coli W wild type (ST1) and mutant strains (ST2 and ST8) were cultivated in shake flasks under aerobic conditions. Wild type strains reached stationary phase with maximum $\mathrm{OD}_{600}$ of 3.7 at $8 \mathrm{~h}$. However, the sugar transporter mutants exhibited a longer lag phase and the exponential phase continued for about $24 \mathrm{~h}$. The maximal $\mathrm{OD}_{600}$ increased about $56 \%$ and $77 \%$ in ST2 and ST8, respectively, compared to ST1 (Fig. 1a). The specific growth rate of ST1 was $0.87 / \mathrm{h}$ while ST2 and ST8 featured $61 \%$ lower specific growth rate $\left(\mu_{\mathrm{ST} 2}: 0.34 / \mathrm{h}\right.$, $\mu_{\mathrm{ST} 8}: 0.33 / \mathrm{h}$ ) (Fig. 1b, Additional file 1: Figure S1). Glucose uptake rate of ST2 and ST8 were reduced by $41 \%$ and $69 \%$, respectively, compared to that of ST1 in the early exponential phase (Fig. 1c). Acetate overflow was relieved. ST1 produced $3.2 \mathrm{~g} / \mathrm{L}$ of acetate during $24 \mathrm{~h}$
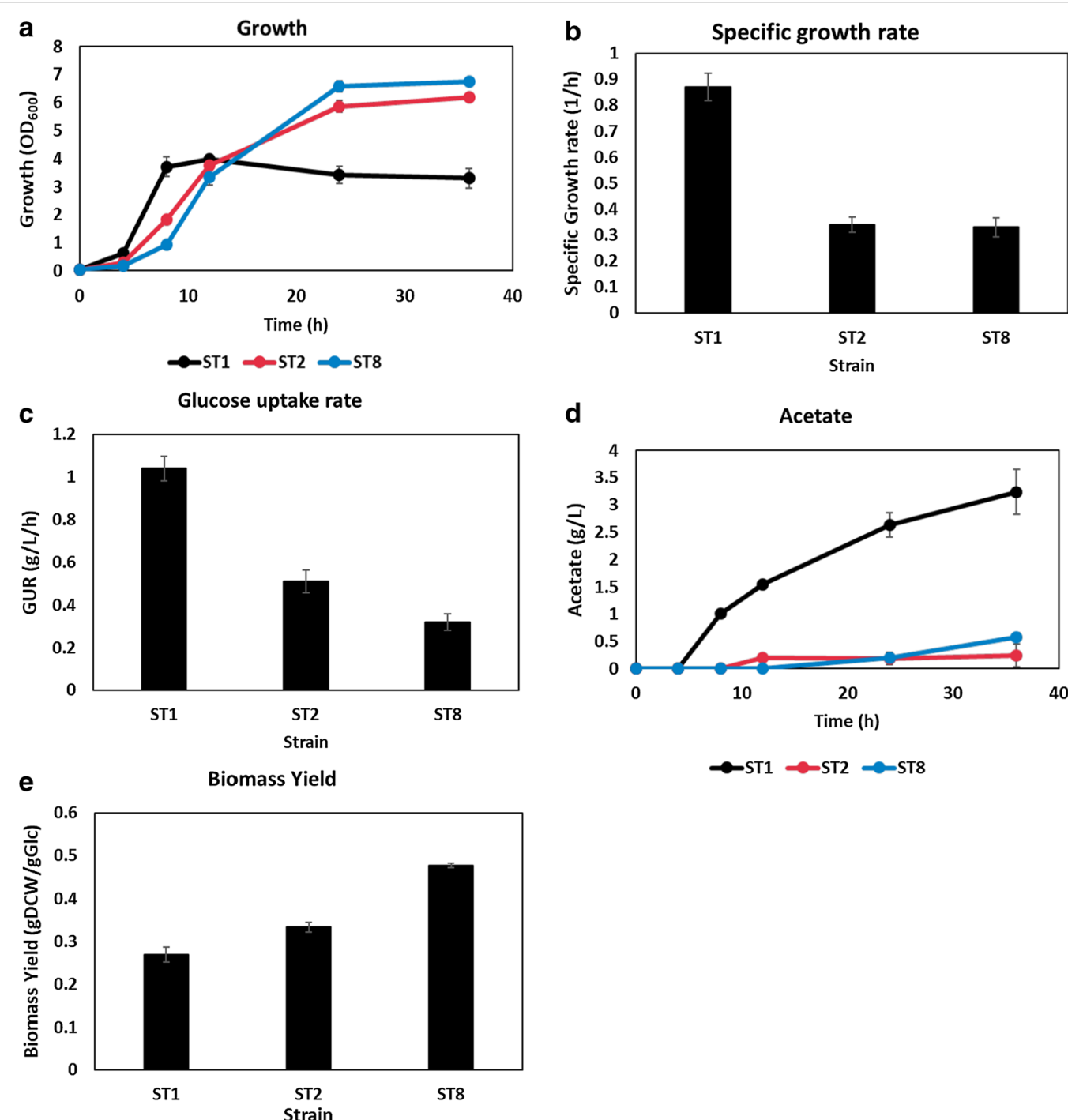

Fig. 1 Wild type (ST1), ptsG mutant (ST2), pts G mglB malE galP mutant (ST8) were cultivated in flasks containing M9 medium. (a) The growth profile and (d) acetate production of ST1, ST2, and ST8 is presented. $\mathbf{b}$ Specific growth rate of strains was measured by monitoring the cell growth every 30 min in exponential phase. c Glucose uptake rates of ST1, ST2, and ST8 were measured in exponential phase. e Biomass yield of strains was calculated after $12 \mathrm{~h}$ cultivation 
cultivation, however, ST2 and ST8 produced much little amount of acetate during $36 \mathrm{~h}$ cultivation $(0.24 \mathrm{~g} / \mathrm{L}$ and $0.57 \mathrm{~g} / \mathrm{L}$ of acetate, respectively) (Fig. 1d). According to the acetate overflow model based on FBA, acetate is produced at a specific growth rate above $0.7-0.8$ $[3,30]$. Therefore, it is reasonable that acetate overflow appeared in ST1 but not in ST2 and ST8. With a decrease in the production of acetate, a major by-product, biomass yield was increased. The biomass yield of ST2 and ST8 increased by $24 \%$ and $77 \%$, respectively, compared to ST1 after $12 \mathrm{~h}$ cultivation (Fig. 1e). This observation accorded closely with previous results in that, improved biomass yield and decreased acetate formation appeared at low glucose uptake rate and growth rate $[17,31]$. The strains with decreased glucose uptake capacity (i.e. sugar transporter mutants) sensed a glucose starved condition, although they were actually in a glucose rich condition. This is similar to the prior report that the mutant strains adapted to low glucose concentration (below $0.15 \mathrm{~g} / \mathrm{L}$ ) led to enhanced biomass yield [32]. Judging from the above results, it is speculated that slowing down the growth rate contributed to the efficient carbon metabolism of the host strain. Furthermore, mutation of PTS and other glucose transporter could influence not only glucose uptake capacity but also global metabolic network. Therefore, it is necessary to investigate which perturbations are connected to the changes in cell physiology.

\section{Transcriptome analysis of sugar transporter mutants}

Various phenotypic changes were accompanied by the deletions in the sugar transporters, The deletions had a strong impact on phenotype as PTS controls the generation of intracellular cAMP by sensing the presence of glucose. Moreover, catabolite repressor/activator (Cra) plays a crucial role as a repressor or activator, in response to the intracellular concentration of fructose 1,6 bisphosphate (F1, 6BP), which affects global gene expression. Transcriptome of wild type and mutant strains were studied to examine alterations in the gene expression profile. Among the 5025 genes from the three samples (wild type ST1, sugar transporter mutants ST2 and ST8), 341 genes, which had an Reads Per Kilobase Million (RPKM) of zero, were excluded and 4684 genes were analyzed. Gene families that displayed expression-foldchange above two were considered as significant results, which accounted for $28 \%$ of the total transcriptome (1317 genes). The genes representing significant gene groups, based on their functions, were classified into four groups for discussion: 1) Central carbon metabolism and respiration (84 genes), 2) alternative transporters (62 genes), 3) quorum sensing, chemotaxis, flagella synthesis $(58$ genes), 4) stress-induced response (15 genes). The fold change value of the transcriptome is displayed in Fig. 2.
The detailed values are tabulated (Additional file 1: Table S2).

\section{Central carbon metabolism and respiration}

When the glucose uptake rate was reduced, the expression of several glycolysis genes was downregulated, while the expression of gluconeogenesis genes was activated. Notably, the expression of eno, pykF, aceE, and aceF, which are enzymes involved in lower glycolysis, were downregulated in both ST2 and ST8. The expression of $f b a B$ and $p p s A$, major enzymes involved in gluconeogenesis, increased remarkably. These results accorded with those of a previous study that Cra represses transcription of eno, pykF, aceE, and aceF, but activates that of $f b a B$ and ppsA [33-35]. However, little change was observed in the transcription of genes related to upper glycolysis, pentose phosphate pathway, and ED pathway in the mutants compared to the wild type strain.

The main acetate generation pathway genes ( $p t a$ and ack) were slightly downregulated but acetate transporter $(a c t P)$ and acetyl-CoA synthase (acs) were strongly activated in the mutant strains. The strong induction of acs in $p t s G$ mutants was previously reported [36]. The actP and acs genes exist in the same operon and are transcriptionally activated by CRP [37]. This suggests that acetate production is diminished significantly in the mutants. Transcription of all genes of the TCA cycle (gltA, $a c n A B$, $i c d$, sucABCD, sdhAB, frdABCD, fum $A B C$, and $m d h$ ) was significantly activated. Given that most of the genes related to the TCA cycle are activated by CRP and Cra, this result corroborates well with the results of preceding studies [38, 39]. Downregulation of PEP carboxylase $(p p c)$ and upregulation of PEP carboxykinase $(p c k)$ were also in accordance with previous reports that transcription of $p p c$ is repressed by Cra, and that of $p c k$ is activated by Cra and CRP $[39,40]$. Interestingly, $a c e A B$ that is activated by Cra and repressed by CRP simultaneously was highly upregulated in the sugar transporter mutants, Kim et al. defined genes regulated in opposite manner by $\mathrm{Cra}$ and CRP, as the "antagonization group" ( $a c e A B, p g k$, $f b a A$, gapA, aceEF), which comply with the action of Cra rather than that of CRP [41]. Unexpectedly, no significant changes were found in the expression of genes related to respiration (nuоABCDEFGHIJKLMN, ndh, cyoABCCD, cydAB, atpABCDEFGH), which are known to be mainly controlled in oxygenic conditions, through $\mathrm{Arc} A B$ and Fnr [42]. It is also reported that the transcription of nuo operon was enhanced by activation of Cra regulators [41]. However, these effects were not observed in the sugar transporter mutants. Overall, it was confirmed that Cra and CAMP-CRP exerted prominent effects on the transcription of key genes related to central metabolism in the sugar transporter mutants. 


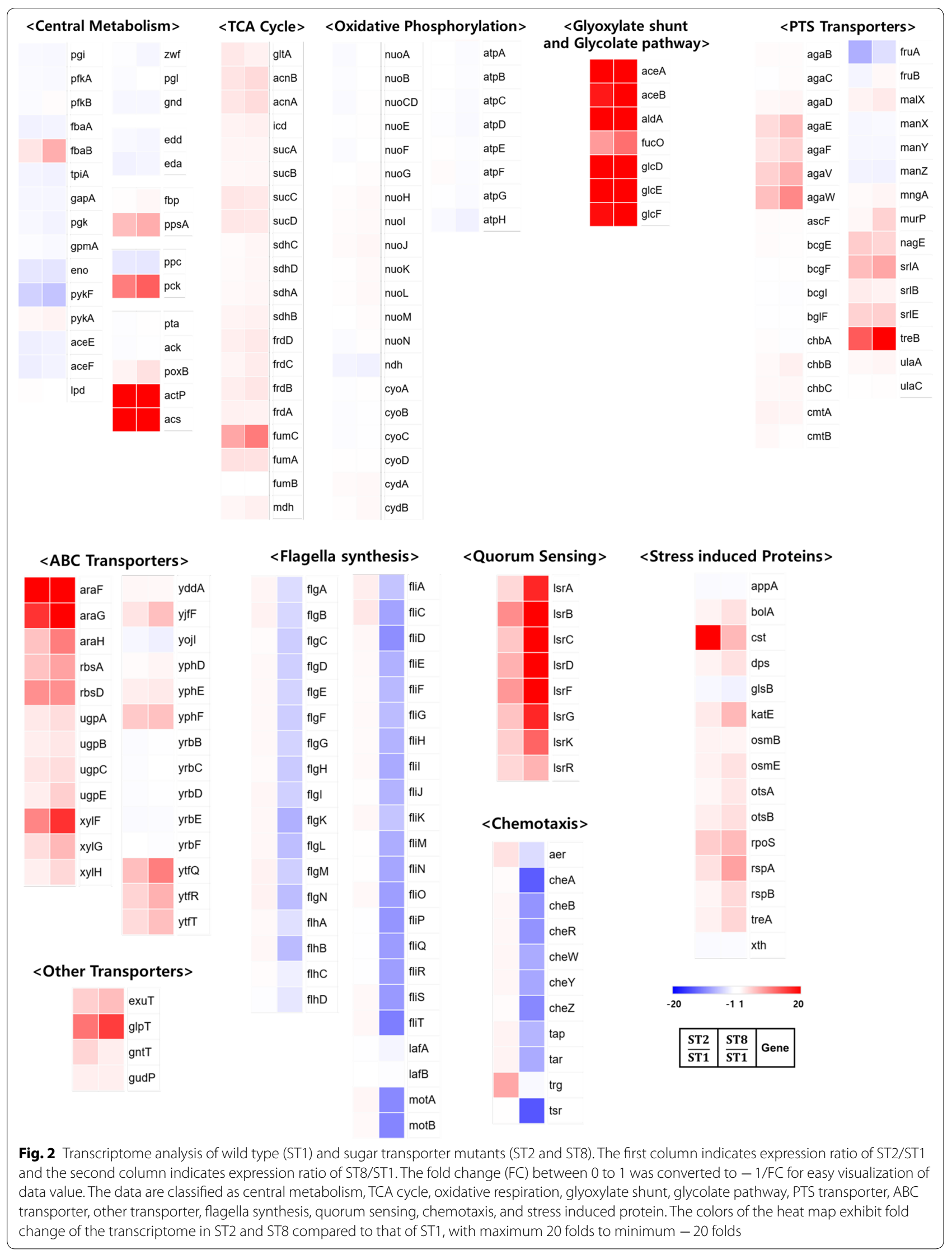




\section{Alternative transporters}

Mutations in major sugar transporter genes led to delayed glucose consumption and extended lag phase. Although most of the crucial glucose transporters were eliminated, the mutant strains still consumed glucose. It is thought that alternative sugar uptake pathways remained functional or were activated in the mutant strains. Several PTS such as treB (PTS for trehalose), srlABE (PTS for glucitol/sorbitol), agaEFVW (PTS for mannose/fructose/ sorbose/N-acetylgalatosamine), nagE (PTS for $\mathrm{N}$-acetylglucosamine), and murP (PTS for $N$-acetylmuramic acid) were upregulated in the sugar transporter mutants. This is consistent with prior reports that transcription of $\operatorname{sr} A B E$, nagE, murP, and agaEFVW are triggered by CRP [43-46]. It is well established that glucose can be imported by mannose and $\mathrm{N}$-acetyl glucosamine PTS [15]. If the specificity of the uptake subunits is relaxed, glucose can be transported by other PTS because the action of phosphorous transfer from PEP is shared by a common subunit, PtsHI. However, transcription of fruAB (PTS for fructose) was downregulated in the mutants, which is thought to be inhibited by increase in Cra in the sugar transporter mutants [39]. In addition, various $\mathrm{ABC}$ transporters, araFGH (Arabinose ABC transporter), $g l p T$ (glycerol-3-phosphate transporter), $r b s A$ (ribose ABC transporter), $x y l F G H$ (xylose ABC transporter), gntT (gluconate transporter), exuT (hexuronate transporter), $y j f F, y p h E F$, and $y t f Q R T$, were upregulated in the mutants. However, additional studies are needed to determine whether any of these activated transporters are actually involved in glucose consumption.

\section{Quorum sensing, chemotaxis, flagella synthesis}

Escherichia coli generates autoinducer-2 (AI-2) as signaling molecules, which interact with several regulators and modulate gene expression, affecting virulence, chemotaxis, and flagella synthesis [47, 48]. It has been documented that the cAMP-CRP complex regulates quorum sensing of several bacterial species such as E. coli, Salmonella enterica, and Vibrio cholerae [49]. Consistently, the transcription of AI-2 permease (LsrABCD), AI-2 kinase (LsrK), and the AI-2 degrading enzymes (LsrG) were activated in the sugar transporter mutants.

Interestingly, transcription of genes related to chemotaxis and flagella synthesis were slightly upregulated in ST2, but significantly downregulated in ST8. When some ligands such as nutrients or metal ions bind to transmembrane receptor proteins connected to histidine kinase (CheA) via a scaffolding protein (CheW), CheACheW complex phosphorylates two response regulators (CheB, CheY). Phosphorylated $\mathrm{CheB}$ and CheY modulate the methylation enzyme, CheR, and flagella motors, respectively [50]. As the major signal transducers in chemotaxis (CheB, CheY) were downregulated, many chemotaxis-related genes (aer, cheA, cheB, cheR, cheW, cheY, cheZ, tap, tar, trg, and tsr) was downregulated in ST8. In addition, master regulator for flagella synthesis, FlhDC, was downregulated in ST8. The reduced chemotaxis activity in sugar transporter mutants was confirmed by cultivation in a semi-solid medium (Additional file 1: Figure S2). Bacterial motility is powered by the proton motive force. In addition, about $8 \%$ of proteins are allocated to synthesize flagellin proteins, and $2 \%$ of total energy is consumed to synthesize and operate the flagella under normal conditions [51]. Considering that substantial energy consumption on flagella synthesis and operation, it is speculated that the cellular ATP and carbon flux was conserved, which could increase biomass yield in the sugar transporter mutants.

Although, it is reported that FlhDC can be activated by CRP, its transcription is also affected by various transcription factors [52]. For example, the expression of flhDC operon was repressed by ppGpp and DksA and ppGpp overrode the activation effect of CRP in poor nutrient conditions, after starvation [53]. Moreover, it was demonstrated that the intracellular concentration of ppGpp increases as growth rate decreases [54]. Therefore, it can be hypothesized that metabolic alteration by ppGpp plays a more significant role in sugar transporter mutants than in wild types. Likewise, the effect of repressors, other than CRP, is thought to be more influential to flagella synthesis in the sugar transporter mutants.

\section{Stress-induced response}

Sugar transporter mutants exhibited extended lag phase, and hardly consumed glucose until early exponential phase. Generally, cells in nutrient starvation activate expression of carbon starvation protein A (Cst) and post-exponential (Pex) proteins. Cst is stimulated in carbon starvation and pex genes are activated by carbon, nitrogen, and phosphorus starvation [55]. It was confirmed that the expression of cst was increased in the sugar transporter mutants in this study. Furthermore, it is reported that expression of stress response genes is regulated by rpoS and its proteolysis is reduced under conditions of carbon starvation [56]. Consequently, RpoS stimulates various stress induced proteins under carbon starvation. We observed that the genes for osmoprotection (otsA, otsB, osmB, osmE, and treA), cell morphology (bolA), and general stress resistance (katE, dps), which are regulated by $\mathrm{RpoS}$, were upregulated, especially, in ST8. This denotes that the mutant strain senses itself to be under starvation conditions, despite the presence of enough glucose in the surroundings.

Bifunctional dehydratase, RspAB, was upregulated in the sugar transporter mutants. It has been demonstrated 
that RspAB induces degradation of homoserine lactone (HSL), which affects the expression of RpoS [57]. E. coli, harboring $r s p A B$ expressing vector, featured reduced acetate production and increased recombinant protein yield [58]. Similar cell physiology was observed in the ST8 strain, in which transcription of $r s p A B$ was activated, but that of rpoS was not affected. These results are not consistent with those of a previous report [58]. However, some other factors, such as elevated level of AI-2 signaling pathway in ST8 strain, could involve in the transcriptional upregulation of RspAB, because it was reported that AI-2 is related to osmotic stress and RpoS regulations $[59,60]$. Further analysis is required to disclose the molecular function of $r s p A B$. Overall, mutations in major glucose transporters caused the microorganisms to sense glucose starvation conditions, which activated stress response, mediated by carbon starvation proteins and stationary phase induced sigma factor (RpoS).

\section{Metabolic flux distribution}

To investigate perturbations in central carbon metabolism by interrupting glucose uptake, metabolic flux distributions of central carbon reactions (Fig. 3; Additional file 1: Table S5) were determined based on production rate of acetic acid and measured MIDs of proteinogenic amino acids (Additional file 1: Table S4). All ${ }^{13} \mathrm{C}$ MFA results of the 3 strains showed statistically acceptable sum of squared residuals (SSR) values (Additional file 1: Table S5) and varying metabolic flux perturbations. Additionally, the contributions of individual pathways to generate key cofactors, such as NADH, $\mathrm{FADH}_{2}, \mathrm{NADPH}$, and ATP, were calculated (Additional file 1: Figure S3) $[20,29,61]$.

We hypothesized that ST1 uptakes glucose mainly through PTS and mutants (ST2, ST8) uptake glucose via non-specific $A B C$ transporters. Glucose uptake through PTS consumes one molecule of PEP, however, that through $A B C$ transporter in mutant requires additional phosphorylation step to introduce glucose to glycolysis metabolism. Therefore, The ATP generation through glycolysis decreased in sugar transporter mutant compared to control strain (Additional file 1: Figure S3). Results of ${ }^{13} \mathrm{C}$ MFA showed decreased glycolysis flux ratio represented by glucose-6-phosphate isomerase (Pgi) from $72.8 \%$ to $52.0 \%$ in the mutants, while the flux ratio of the pentose phosphate and ED pathways, represented by glucose-6-phosphate dehydrogenase (Zwf), was increased [62, 63]. The higher pentose phosphate pathway flux in mutant strains clearly contributed to higher biomass yield by increasing NADPH production. The contribution of NADPH generation by transhydrogenase continuously decreased from $41 \%$ to $13 \%$ buffering the NADPH

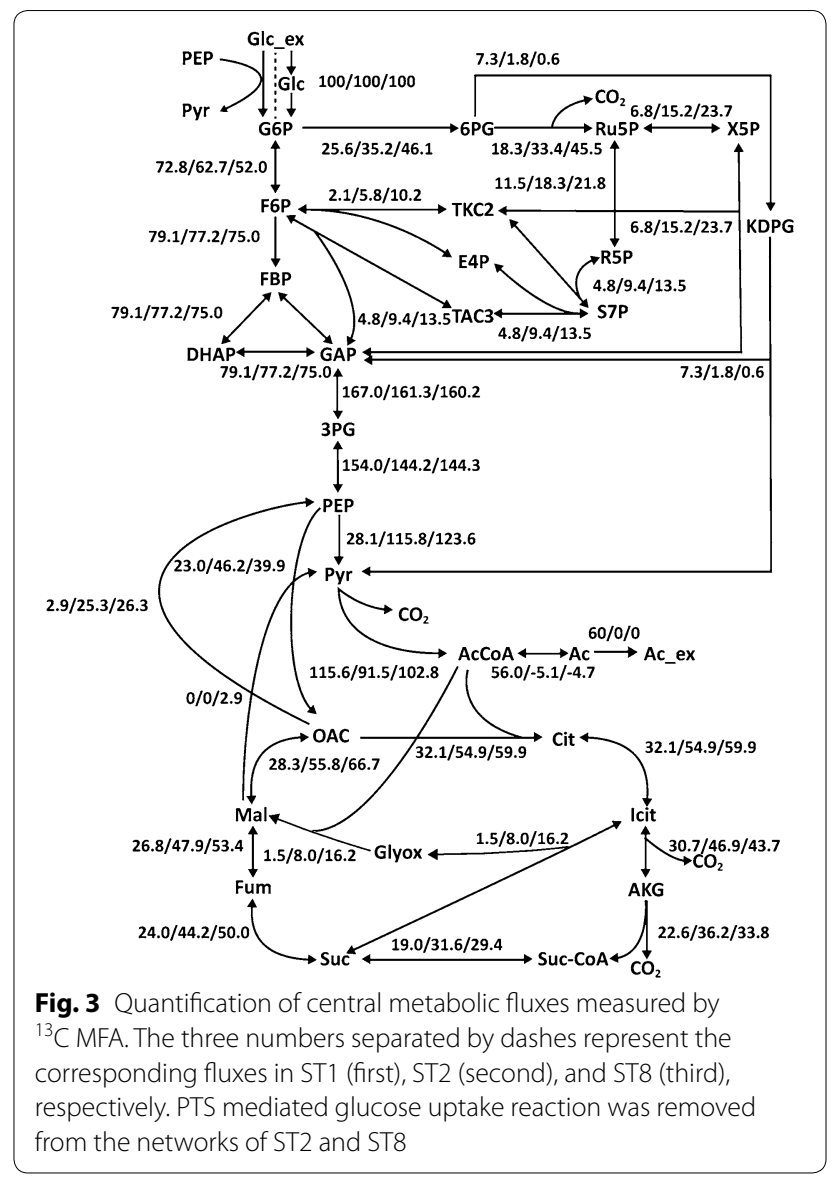

perturbations (Additional file 1: Figure S1) [64]. Moreover, the flux ratio in citrate synthase, the first step of TCA cycle, was significantly increased in ST2 and ST8. Interestingly, a significant portion of the TCA cycle flux was directed to the glyoxylate shunt pathway, which was activated from $1.5 \%$ (ST1) to $8.0 \%$ and $16.2 \%$ in ST2 and ST8, respectively. As a result, the mutant strains showed slightly increased TCA cycle-dependent $\mathrm{NADH} / \mathrm{FADH}_{2}$ generation $(4.2 \%$ in ST2 and $6.8 \%$ in ST8) compared with the control strain (Additional file 1: Figure S3), although all the TCA cycle genes were highly upregulated in the mutants according to the transcriptomics data. Further, ATP formation ratio via oxidative phosphorylation was moderately enhanced in ST2 and ST 8 by $15.5 \%$ and $16.7 \%$, respectively (Additional file 1: Figure S3). ST1 synthesized ATP by converting acetyl-CoA to acetate, while the mutant strains used ATP for assimilating acetate. From transcriptomics data, transcription level of acs was highly increased in mutant strains and the corresponding flux ratio was $56 \%$ in ST1, but $-5.1 \%$ in ST2 and $-4.7 \%$ ST8, respectively. It is speculated that the metabolic perturbation in the sugar transporter mutants resulted not only in 
increased ATP generation from the electron transfer chain, but also in carbon conservation through the glyoxylate shunt pathway.

\section{Application of the mutants for metabolite production (EGFP, GABA, and lycopene)}

The sugar transporter mutants exhibited: (1) improved biomass yield and reduced acetate formation, (2) strengthened TCA cycle and gluconeogenesis, (3) improved ATP conservation by losing motility. These characteristics of the sugar transporter mutants are likely to be helpful in the production of several value-added compounds.

First, we attempted to take advantage of these effects in the production of recombinant proteins because the host strain produced less acetate but yielded enough amino acids and ATP. Several research groups have successfully reduced acetate production, with a subsequent increase in the production of recombinant proteins, such as DNA vaccines and glutamate dehydrogenase, in $p t s G$ mutants $[31,65]$. The plasmid containing the EGFP encoding gene under a constitutive promoter, was introduced into ST1, ST2, and ST8 and the resulting strains were named as STE1, STE2, and STE8, respectively. A retardation in growth rate was observed in STE2 and STE8, but eventually $35 \%$ higher maximum cell mass $\left(\mathrm{OD}_{600}\right)$ compared to STE1, was achieved in both strains (Fig. 4a). STE2 and STE8 produced $49 \%$ and $77 \%$ lower acetate, respectively, at the end of cultivation (Fig. 4b). To quantify the intracellular EGFP expression, fluorescence intensity was measured. The linearity between the intensity of fluorescence intensity and fluorescent protein concentration has been demonstrated in previous report [66]. Interestingly, fluorescence intensity was enhanced about $160 \%$ and $282 \%$ in STE2 and STE8, respectively (Fig. 4c), resulting in a corresponding increase of $35 \%$ and $132 \%$ in the specific yields of EGFP, when calculated in the early stationary phase (Fig. 4d).

Higher TCA cycle fluxes in the sugar transporter mutants are thought to be beneficial for the production of TCA cycle derived products. Indeed, improved production of succinate was reported when the glucose PTS component was mutated [67]. We attempted the same in our sugar transporter mutants during GABA production under aerobic conditions. GABA is derived from $\alpha$-ketoglutarate, an intermediate of the TCA cycle,

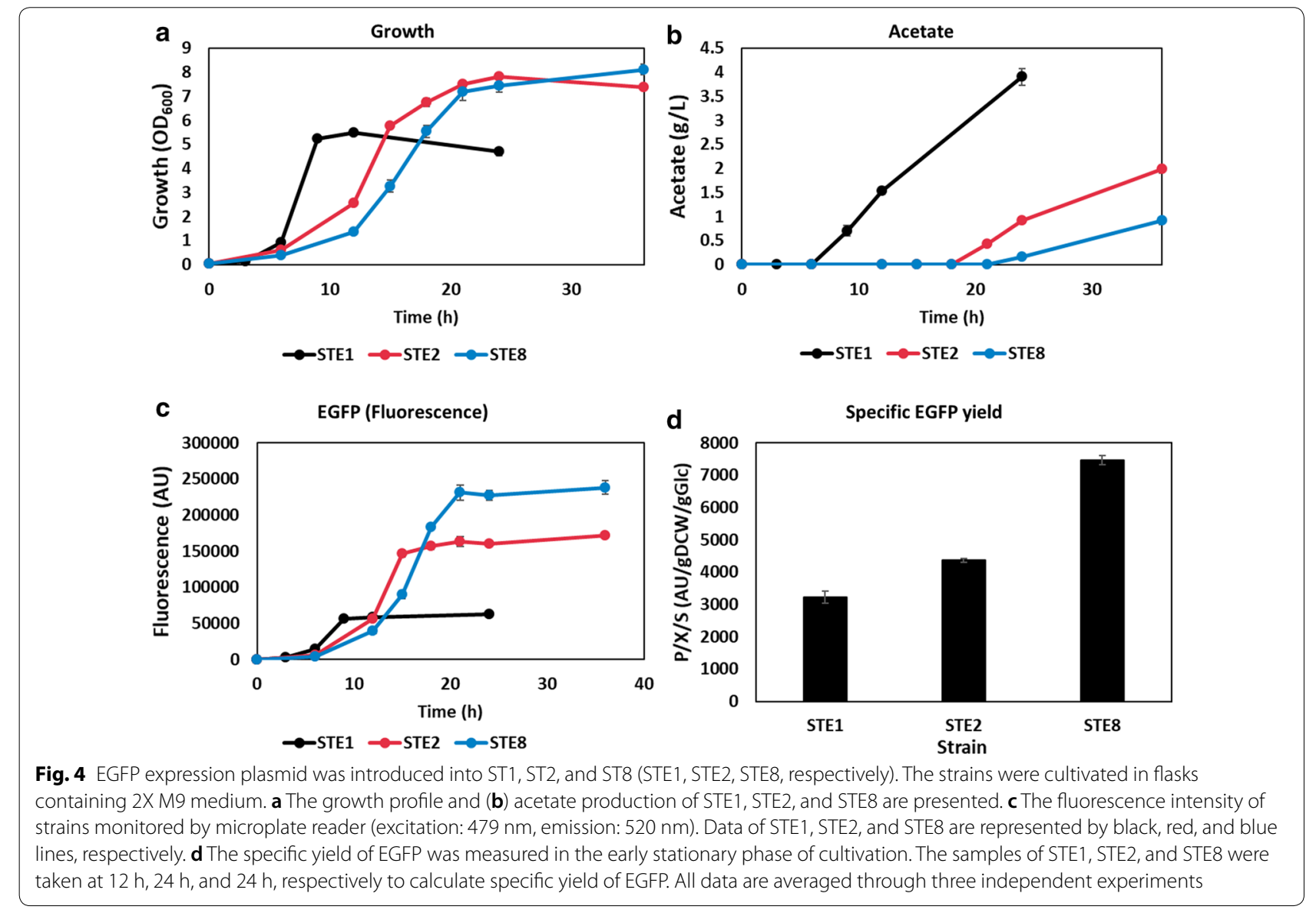


through a two-step enzyme reaction. Plasmids, GadB ${ }^{\text {mut }}$ (Glu89Gln/D452-466) and GadC $C^{m u t}(1-470)$, were constructed for the expression of glutamate synthases from Corynebacterium glutamicum ATCC 13032, and introduced into ST1, ST2, and ST8. Furthermore, gabT was deleted to prevent degradation of GABA to succinate semialdehyde, and the resulting strains were named as STG1, STG2, and STG8, respectively. STG2 and STG8 exhibited retarded growth but improved maximum biomass production, compared to STG1 (Fig. 5a). Predictably, acetate production was decreased by about $75 \%$ and 61\% in STG2 and STG8, respectively (Fig. 5b). Final GABA titers of STG2 and STG8 were $119 \%$ and $130 \%$ higher than that of STG1 (Fig. 5c), with improved specific GABA yields by $61 \%$ and $176 \%$, respectively (Fig. $5 \mathrm{~d}$ ).

Further, lycopene producing strains were constructed. It has been documented that ptsG mutants showed higher production of lycopene compared to the parental strain, however, the mechanism was not suggested in a prior study [68]. Another study demonstrated that activation of $p p s A$ and repression of gapA were attempted to balance intracellular G3P and pyruvate, precursors of MEP pathway [69]. According to our transcriptome analysis, transcription of gapA was downregulated and that of
ppsA was upregulated in the sugar transporter mutants. Lycopene pathway harboring plasmids were introduced into ST1, ST2, and ST8, which were named as STL1, STL2, and STL8, respectively. Extended lag phase was observed in STL2 and STL8 compared to that in STL1 (Fig. 6a). STL1 produced $5 \mathrm{~g} / \mathrm{L}$ of acetate at the end of cultivation, however, STL2 and STL8 produced no acetate at all (Fig. 6b). The final lycopene titers were $96 \%$ and 132\% higher in STL2 and STL8 (Fig. 6c), respectively. The specific lycopene yield of STL2 and STL8 was improved about $35 \%$ and $90 \%$, respectively, as compared to that of STL1, in the stationary phase (Fig. 6d). It maybe envisaged that not only the enhanced biomass yield, but also the increased PPP flux, probably contributed to NADPH supply for lycopene production in the sugar transporter mutants.

In this study, reduced glucose uptake rate for increased efficacy of cellular metabolism was investigated. The optimization of carbon source uptake rate was indeed beneficial to efficient growth and metabolite production. However, lower glucose uptake featured extended lag phase of strains, which can cause low productivity problems. Therefore, fine-tuning of substrate uptake rate would be required for establishing speed and efficiency of

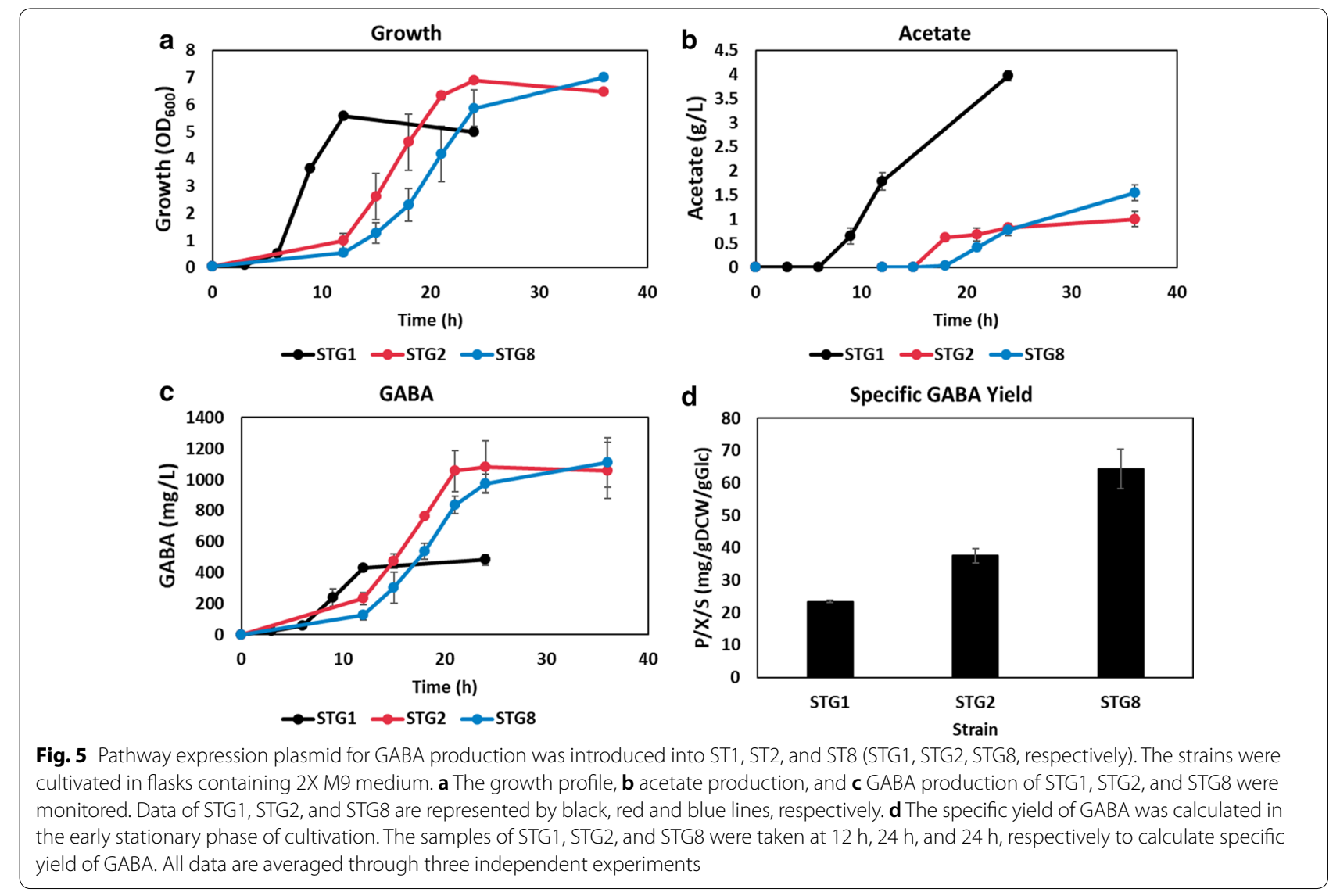



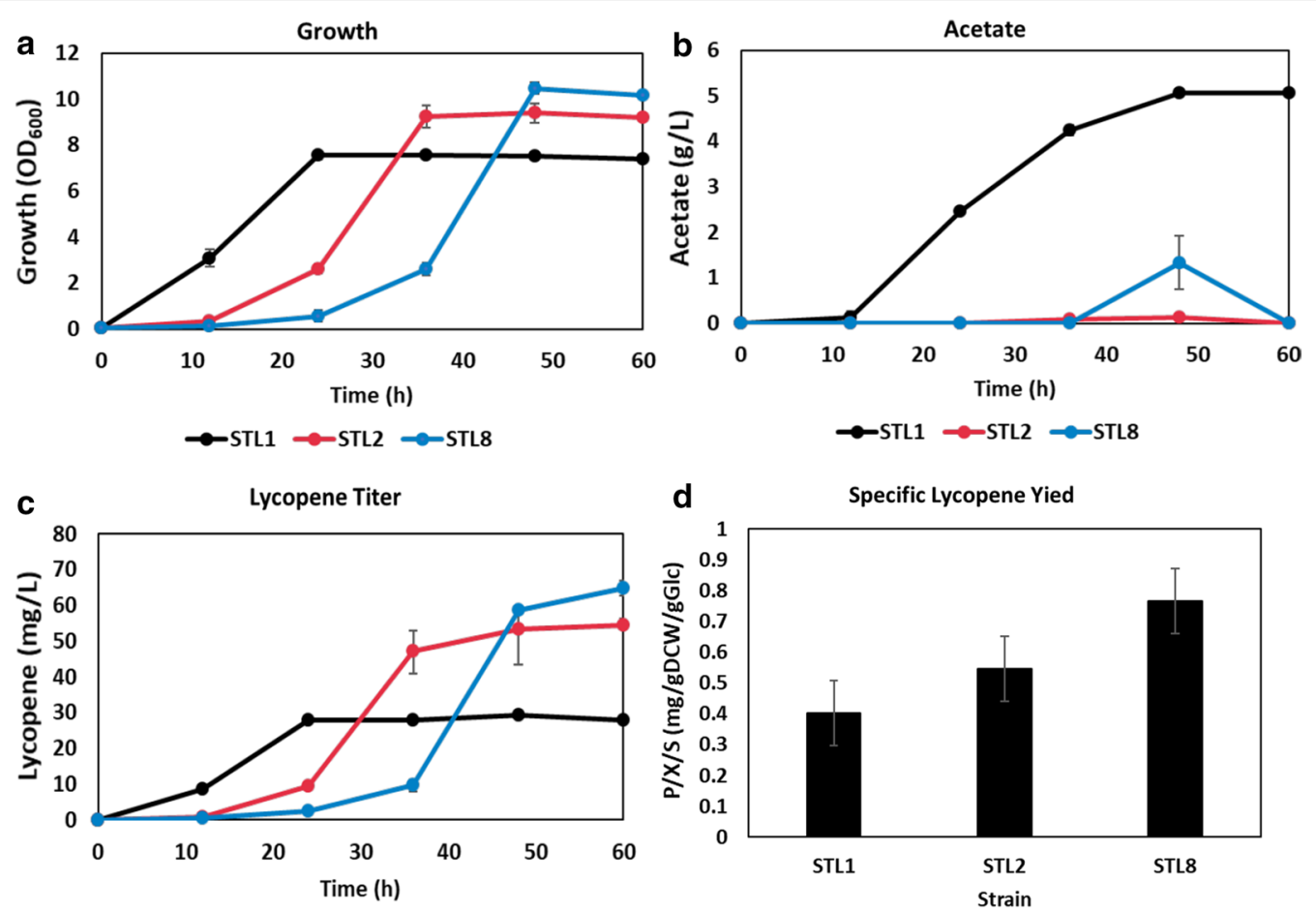

Fig. 6 Plasmid with the lycopene pathway was introduced into ST1, ST2, and ST8 (STL1, STL2, STL8, respectively). The strains were cultivated in flasks containing 2X M9 medium. a The growth profile, $\mathbf{b}$ acetate production, and $\mathbf{c}$ lycopene production of STL1, STL2, and STL8 are presented. Data of STL1, STL2, and STL8 are represented by black, red, and blue lines, respectively. $\mathbf{d}$ The specific yield of lycopene was calculated in the early stationary phase of cultivation. The samples of STL1, STL2, and STL8 were taken at $24 \mathrm{~h}, 36 \mathrm{~h}$, and $48 \mathrm{~h}$, respectively to calculate specific yield of lycopene. All data are averaged through three independent experiments

metabolism of industrial strains. Recent advances in the methods for selection of slow-growing microbes using CRISPRi technology [70] and laboratory evolution, have been applied to rebalance cellular metabolism [71] and could be solutions for development of industrial strains optimized for metabolite production.

\section{Conclusions}

Bacterial growth is closely related to the uptake of carbon sources. Although investigations involving sugar transporter mutants have been carried out in the past, not many studies exist on the physiology of the mutants. The development of omics technology allows us better understanding of intracellular events. Through transcriptome analysis, we found that global gene expression in the sugar transporter mutants was mainly regulated via cAMP-CRP and Cra. Transcription of alternative sugar transporters was upregulated, while chemotaxis response and motility were downregulated, which resulted in the conservation of cellular ATP. Furthermore, stress induced responses also affected the modulation of cellular metabolism.
Changes in the intracellular metabolic flux were validated through ${ }^{13} \mathrm{C}$ MFA. Through comprehensive analysis, we concluded that sugar transporter mutants can be an excellent chassis for production of several valueadded compounds related to biomass and TCA cycle derivatives. Most of the high throughput enrichment in metabolic engineering for metabolites production is based on the screening of superior growth. However, our results showed the advantage of slow metabolism on bacterial growth and metabolites production. This research can be a good example of systematic approach for practical metabolic engineering.

\section{Supplementary information}

Supplementary information accompanies this paper at https://doi. org/10.1186/s12934-019-1224-8.

Additional file 1: Table S1. Oligomers used in this study. Table S2. Transcriptome data for ST2, ST8 VS ST1. Table S3. Metabolic network model of E. coli used for ${ }^{13} \mathrm{C}-\mathrm{MFA}$. Table S4. Mass isotopomer distributions from E. coli grown in batch cultures with ${ }^{12-13} \mathrm{C}$-labeled glucose. Table S5. Results of ${ }^{13} \mathrm{C}$-metabolic flux analysis for E. coli grown in batch cultures with ${ }^{12-13} \mathrm{C}$-labeled glucose. Figure S1. The growth curve of ST1, ST2, and ST8 in exponential phase. Figure S2. Motility of ST1, ST2 and ST8 
in M9 semi-solid agar. Figure S3. Normalized cofactor balance based on ${ }^{13}$ C-MFA results.

\section{Acknowledgements}

Not applicable.

\section{Authors' contributions}

HMJ, DKI contributed equally to this work. HMJ, GYJ and MKO conceived the idea and $\mathrm{HMJ}, \mathrm{DKI}$ and $\mathrm{MKO}$ wrote the manuscript. HMJ, DKI and JHL performed experiments. All authors read and approved the final manuscript.

\section{Funding}

This research was supported by the National Research Foundation of Korea funded by the Korean Government (2012M1A2A2026560 and 2017R1A2B4008758).

\section{Availability of data and materials}

All data generated or analyzed during this study are included in this published article and its additional files.

\section{Ethics approval and consent to participate}

Not applicable.

\section{Consent for publication}

Not applicable.

\section{Competing interests}

The authors declare that they have no competing interests.

\section{Author details}

${ }^{1}$ Department of Chemical and Biological Engineering, Korea University, 145 Anam-ro, Seongbuk-gu, Seoul 02841, South Korea. ${ }^{2}$ Department of Chemical Engineering, Pohang University of Science and Technology, 77 Cheongam-ro, Nam-gu, Pohang, Gyeongbuk 37673, South Korea. ${ }^{3}$ School of Interdisciplinary Bioscience and Bioengineering, Pohang University of Science and Technology, 77 Cheongam-ro, Nam-gu, Pohang, Gyeongbuk 37673, South Korea.

Received: 26 August 2019 Accepted: 29 September 2019

Published online: 10 October 2019

\section{References}

1. Hagman A, Piskur J. A study on the fundamental mechanism and the evolutionary driving forces behind aerobic fermentation in yeast. PLoS ONE. 2015;10:e0116942

2. Piskur J, Rozpedowska E, Polakova S, Merico A, Compagno C. How did Saccharomyces evolve to become a good brewer? Trends Genet. 2006;22:183-6.

3. Basan M, Hui S, Okano H, Zhang Z, Shen Y, Williamson JR, Hwa T. Overflow metabolism in Escherichia coli results from efficient proteome allocation. Nature. 2015:528:99-104.

4. Liberti MV, Locasale JW. The Warburg effect: how does it benefit cancer cells? Trends Biochem Sci. 2016;41:211-8.

5. Pfeiffer T, Morley A. An evolutionary perspective on the Crabtree effect. Front Mol Biosci. 2014;1:17.

6. Niebel B, Leupold S, Heinemann M. An upper limit on Gibbs energy dissipation governs cellular metabolism. Nat Metabol. 2019;1:125-32.

7. Szenk M, Dill KA, de Graff AMR. Why do fast-growing bacteria enter overflow metabolism? Testing the membrane real estate hypothesis. Cell Syst. 2017:5:95-104

8. Karlin S, Mrazek J, Campbell A, Kaiser D. Characterizations of highly expressed genes of four fast-growing bacteria. J Bacteriol. 2001;183:5025-40.

9. Pei L, Schmidt M. Fast-growing engineered microbes: new concerns for gain-of-function research? Front Genet. 2018;9:207.

10. Vemuri GN, Altman E, Sangurdekar DP, Khodursky AB, Eiteman MA. Overflow metabolism in Escherichia coli during steady-state growth: transcriptional regulation and effect of the redox ratio. Appl Environ Microbiol. 2006;72:3653-61.

11. Jansen ML, Diderich JA, Mashego M, Hassane A, de Winde JH, DaranLapujade P, Pronk JT. Prolonged selection in aerobic, glucose-limited chemostat cultures of Saccharomyces cerevisiae causes a partial loss of glycolytic capacity. Microbiology. 2005;151:1657-69.

12. Kayser A, Weber J, Hecht V, Rinas U. Metabolic flux analysis of Escherichia coli in glucose-limited continuous culture. I. Growth-rate dependent metabolic efficiency at steady state. Microbiology. 2005;151:693-706.

13. Lendenmann U, Egli T. Is Escherichia coli growing in glucose-limited chemostat culture able to utilize other sugars without lag. Microbiology. 1995;141:71-8

14. Saier MH. The bacterial phosphotransferase system: new frontiers 50 years after tts discovery. J Mol Microbiol Biotechnol. 2015;25:73-8.

15. Green J, Stapleton MR, Smith LJ, Artymiuk PJ, Kahramanoglou C, Hunt DM, Buxton RS. Cyclic-AMP and bacterial cyclic-AMP receptor proteins revisited: adaptation for different ecological niches. Curr Opin Microbiol. 2014;18:1-7.

16. Jahreis K, Pimentel-Schmitt EF, Bruckner R, Titgemeyer F. Ins and outs of glucose transport systems in eubacteria. FEMS Microbiol Rev. 2008:32:891-907.

17. Steinsiek S, Bettenbrock K. Glucose transport in Escherichia coli mutant strains with defects in sugar transport systems. J Bacteriol. 2012:194:5897-908.

18. Itsko M, Schaaper RM. Transcriptome analysis of Escherichia coli during dGTP starvation. J Bacteriol. 2016;198:1631-44.

19. Oh MK, Rohlin L, Kao KC, Liao JC. Global expression profiling of acetategrown Escherichia coli. J Biol Chem. 2002;277:13175-83.

20. Long CP, Gonzalez JE, Feist AM, Palsson BO, Antoniewicz MR. Fast growth phenotype of E. coli K-12 from adaptive laboratory evolution does not require intracellular flux rewiring. Metab Eng. 2017:44:100-7.

21. Fischer E, Sauer U. Metabolic flux profiling of Escherichia coli mutants in central carbon metabolism using GC-MS. Eur J Biochem. 2003;270:880-91.

22. Datsenko KA, Wanner BL. One-step inactivation of chromosomal genes in Escherichia coli K-12 using PCR products. Proc Natl Acad Sci USA. 2000;97:6640-5.

23. Antoniewicz MR, Kelleher JK, Stephanopoulos G. Accurate assessment of amino acid mass isotopomer distributions for metabolic flux analysis. Anal Chem. 2007:79:7554-9.

24. Leighty RW, Antoniewicz MR. COMPLETE-MFA: complementary parallel labeling experiments technique for metabolic flux analysis. Metab Eng. 2013;20:56-62

25. Antoniewicz MR, Kelleher JK, Stephanopoulos G. Elementary metabolite units (EMU): a novel framework for modeling isotopic distributions. Metab Eng. 2007:9:68-86

26. Young JD. INCA: a computational platform for isotopically non-stationary metabolic flux analysis. Bioinformatics. 2014;30:1333-5.

27. Antoniewicz MR, Kelleher JK, Stephanopoulos G. Determination of confidence intervals of metabolic fluxes estimated from stable isotope measurements. Metab Eng. 2006:8:324-37.

28. Crown SB, Long CP, Antoniewicz MR. Integrated C-13-metabolic flux analysis of 14 parallel labeling experiments in Escherichia coli. Metab Eng. 2015;28:151-8

29. He L, Xiao Y, Gebreselassie N, Zhang FZ, Antoniewicz MR, Tang YJJ, Peng LF. Central metabolic responses to the overproduction of fatty acids in Escherichia coli based on C-13-metabolic flux analysis. Biotechnol Bioeng. 2014;111:575-85.

30. Zeng $\mathrm{H}$, Yang A. Modelling overflow metabolism in Escherichia coli with flux balance analysis incorporating differential proteomic efficiencies of energy pathways. BMC Syst Biol. 2019;13:3.

31. Fuentes $L G$, Lara AR, Martinez LM, Ramirez OT, Martinez A, Bolivar F, Gosset G. Modification of glucose import capacity in Escherichia coli: physiologic consequences and utility for improving DNA vaccine production. Microb Cell Fact. 2013;12:42.

32. Heyland J, Fu J, Blank LM, Schmid A. Quantitative physiology of Pichia pastoris during glucose-limited high-cell density fed-batch cultivation for recombinant protein production. Biotechnol Bioeng. 2010;107:357-68.

33. Bledig SA, Ramseier TM, Saier MH Jr. FruR mediates catabolite activation of pyruvate kinase (pykF) gene expression in Escherichia coli. J Bacteriol. 1996:178:280-3. 
34. Shimada T, Fujita N, Maeda M, Ishihama A. Systematic search for the Cra-binding promoters using genomic SELEX system. Genes Cells. 2005; 10:907-18

35. Son YJ, Phue JN, Trinh LB, Lee SJ, Shiloach J. The role of Cra in regulating acetate excretion and osmotic tolerance in E. coli $\mathrm{K}-12$ and E. coli B at high density growth. Microb Cell Fact. 2011;10:52.

36. Baptist G, Pinel C, Ranquet C, Izard J, Ropers D, de Jong H, Geiselmann $J$. A genome-wide screen for identifying all regulators of a target gene. Nucleic Acids Res. 2013:41:e164.

37. Beatty CM, Browning DF, Busby SJW, Wolfe AJ. Cyclic AMP receptor protein-dependent activation of the Escherichia coli acsP2 promoter by a synergistic class III mechanism. J Bacteriol. 2003;185:5148-57.

38. Tsai MJ, Wang JR, Yang CD, Kao KC, Huang WL, Huang HY, Tseng CP, Huang HD, Ho SY. PredCRP: predicting and analysing the regulatory roles of CRP from its binding sites in Escherichia coli. Sci Rep. 2018;8:951.

39. Shimada T, Yamamoto $\mathrm{K}$, Ishihama A. Novel members of the $\mathrm{Cra}$ regulon involved in carbon metabolism in Escherichia coli. J Bacteriol. 2011;193:649-59.

40. Nakano M, Ogasawara H, Shimada T, Yamamoto K, Ishihama A. Involvement of CAMP-CRP in transcription activation and repression of the $p c k$ gene encoding PEP carboxykinase, the key enzyme of gluconeogenesis. FEMS Microbiol Lett. 2014;355:93-9.

41. Kim D, Seo SW, Gao Y, Nam H, Guzman Gl, Cho BK, Palsson BO. Systems assessment of transcriptional regulation on central carbon metabolism by Cra and CRP. Nucleic Acids Res. 2018;46:2901-17.

42. Shalel-Levanon S, San KY, Bennett GN. Effect of oxygen, and ArcA and FNR regulators on the expression of genes related to the electron transfer chain and the TCA cycle in Escherichia coli. Metab Eng. 2005;7:364-74.

43. Jaeger $T$, Mayer $C$. The transcriptional factors MurR and catabolite activator protein regulate $\mathrm{N}$-acetylmuramic acid catabolism in Escherichia coli. J Bacteriol. 2008;190:6598-608.

44. Plumbridge J, Kolb A. DNA loop formation between nag repressor molecules bound to its 2 operator sites is necessary for repression of the Nag regulon of Escherichia coli in-vivo. Mol Microbiol. 1993;10:973-81.

45. Ray WK, Larson TJ. Application of AgaR repressor and dominant repressor variants for verification of a gene cluster involved in $\mathrm{N}$-acetylgalactosamine metabolism in Escherichia coli K-12. Mol Microbiol. 2004;51:813-26.

46. Zheng DL, Constantinidou C, Hobman JL, Minchin SD. Identification of the CRP regulon using in vitro and in vivo transcriptional profiling. Nucleic Acids Res. 2004;32:5874-93.

47. Barrios AFG, Zuo RJ, Hashimoto Y, Yang L, Bentley WE, Wood TK. Autoinducer 2 controls biofilm formation in Escherichia coli through a novel motility quorum-sensing regulator (MqsR, B3022). J Bacteriol. 2006;188:305-16

48. Pereira CS, Thompson JA, Xavier KB. Al-2-mediated signalling in bacteria. FEMS Microbiol Rev. 2013:37:156-81.

49. Wang L, Hashimoto Y, Tsao CY, Valdes JJ, Bentley WE. Cyclic AMP (CAMP) and CAMP receptor protein influence both synthesis and uptake of extracellular autoinducer 2 in Escherichia coli. J Bacteriol. 2005;187:2066-76.

50. Falke JJ, Bass RB, Butler SL, Chervitz SA, Danielson MA. The two-component signaling pathway of bacterial chemotaxis: a molecular view of signal transduction by receptors, kinases, and adaptation enzymes. Annu Rev Cell Dev Biol. 1997;13:457-512.

51. Zhao K, Liu MZ, Burgess RR. Adaptation in bacterial flagellar and motility systems: from regulon members to 'foraging'-like behavior in E. coli. Nucleic Acids Res. 2007;35:4441-52.

52. Amores GR, Heras AD, Sanches-Medeiros A, Elfick A, Silva-Rocha R. Systematic identification of novel regulatory interactions controlling biofilm formation in the bacterium Escherichia coli. Sci Rep. 2017;7:16768.

53. Lemke JJ, Durfee T, Gourse RL. DksA and ppGpp directly regulate transcription of the Escherichia coli flagellar cascade. Mol Microbiol. 2009:74:1368-79.
54. Shimizu K, Matsuoka Y. Regulation of glycolytic flux and overflow metabolism depending on the source of energy generation for energy demand. Biotechnol Adv. 2019;37:284-305.

55. Chung HJ, Bang W, Drake MA. Stress response of Escherichia coli. Compr Rev Food Sci F. 2006;5:52-64.

56. Hengge-Aronis R. Signal transduction and regulatory mechanisms involved in control of the sigma(S) (RpoS) subunit of RNA polymerase. Microbiol Mol Biol Rev. 2002;66:373-95.

57. Huisman GW, Kolter R. Sensing starvation-a homoserine lactonedependent signaling pathway in Escherichia coli. Science. 1994;265:537-9.

58. Weikert C, Canonaco F, Sauer U, Bailey JE. Co-overexpression of RspAB improves recombinant protein production in Escherichia coli. Metab Eng. 2000;2:293-9.

59. Holland AM, Rather PN. Evidence for extracellular control of RpoS proteolysis in Escherichia coli. FEMS Microbiol Lett. 2008;286:50-9.

60. Park H, Lee K, Yeo S, Shin H, Holzapfel WH. Autoinducer-2 quorum sensing influences viability of Escherichia coli O157:H7 under osmotic and in vitro gastrointestinal stress conditions. Front Microbiol. 2017;8:1077.

61. Long CP, Gonzalez JE, Feist AM, Palsson BO, Antoniewicz MR. Dissecting the genetic and metabolic mechanisms of adaptation to the knockout of a major metabolic enzyme in Escherichia coli. Proc Natl Acad Sci USA. 2018;115:222-7.

62. Meza E, Becker J, Bolivar F, Gosset G, Wittmann C. Consequences of phosphoenolpyruvate: sugar phosphotransferase system and pyruvate kinase isozymes inactivation in central carbon metabolism flux distribution in Escherichia coli. Microb Cell Fact. 2012;11:127

63. Flores S, Gosset G, Flores N, de Graaf AA, Bolivar F. Analysis of carbon metabolism in Escherichia coli strains with an inactive phosphotransferase system by C-13 labeling and NMR spectroscopy. Metab Eng. 2002;4:124-37.

64. Chou HH, Marx CJ, Sauer U. Transhydrogenase promotes the robustness and evolvability of E. coli deficient in NADPH production. Plos Genet. 2015;11:e1005007.

65. Cheng LK, Yang XY, Li SG, Fu Q, Fu SJ, Wang JL, Li F, Lei LC, Shen ZQ. Impact of gene modification of phosphotransferase system on expression of glutamate dehydrogenase protein of Streptococcus suis in Escherichia coli. Biotechnol Biotec Eq. 2017;31:612-8.

66. Lo CA, Kays I, Lin TJ, Cvetkovaska V, Chen BE. Quantification of protein levels in single living cells. Cell Rep. 2015;13:2634-44.

67. Liang Q, Zhang F, Li Y, Zhang X, Li J, Yang P, Qi Q. Comparison of individual component deletions in a glucose-specific phosphotransferase system revealed their different applications. Sci Rep. 2015:5:13200.

68. Zhang CQ, Chen XX, Zou RY, Zhou K, Stephanopoulos G, Too HP. Combining genotype improvement and statistical media optimization for isoprenoid production in E. coli. Plos ONE. 2013;8:e75164.

69. Jung J, Lim JH, Kim SY, Im DK, Seok JY, Lee SJV, Oh MK, Jung GY. Precise precursor rebalancing for isoprenoids production by fine control of gapA expression in Escherichia coli. Metab Eng. 2016;38:401-8.

70. Beuter D, Gomes JV, Randau L, Diaz-Pascual F, Drescher K, Link H. Selective enrichment of slow-growing bacteria in a metabolism-wide CRISPRi library with a TIMER protein. ACS Synth Biol. 2018;7:2775-82.

71. Choe D, Lee JH, Yoo M, Hwang S, Sung BH, Cho S, Palsson B, Kim SC, Cho BK. Adaptive laboratory evolution of a genome-reduced Escherichia coli. Nat Commun. 2019;10:935.

\section{Publisher's Note}

Springer Nature remains neutral with regard to jurisdictional claims in published maps and institutional affiliations. 